\title{
Surgical management of children and young adults with the Wolff-Parkinson-White syndrome
}

\author{
Macdonald Dick II, Ara Vaporicyan, Edward L. Bove, Fred Morady, William A. Scott, Burt I. Bromberg, \\ Gerald A. Serwer, Steven F. Bolling, Douglas M. Behrendt, and Amnon Rosenthal \\ Division of Pediatric Cardiology and Section of Thoracic Surgery, C. S. Mott Children's Hospital, and the Departments of \\ Pediatrics, Surgery, and Internal Medicine, University of Michigan, Ann Arbor, Michigan, USA
}

\begin{abstract}
Summary. The Wolff-Parkinson-White syndrome, as originally described, includes palpitations, tachycardia, and an abnormal electrocardiogram (short PR interval and wide QRS complex). The clinical manifestations are dependent upon a reentrant tachycardia supported by an accessory connection bridging the atrioventricular junction and frequently appear during the first two decades of life. Palpitations are the usual symptoms; less frequently, severe symptoms, such as syncope and sudden death, may result from very rapid atrioventricular conduction across the accessory connection during atrial fibrillation. We report the surgical management of 30 young patients with this syndrome, including 6 with life-threatening tachycardia. Surgical interruption of the accessory connection(s) was curative in $90 \%(27 / 30)$ of the patients; lifethreatening symptoms were eliminated in the other three. Based on the limited knowledge of the natural history of the Wolff-Parkinson-White syndrome, the individual patient symptoms, and the electrophysiologic properties of each patient's accessory pathway(s), an algorithm is presented outlining the treatment options. This experience strongly suggests that surgical treatment of the Wolff-ParkinsonWhite syndrome is safe, effective, and possibly the preferred treatment for this disorder in selected young symptomatic patients.
\end{abstract}

Key words: Wolff-Parkinson-White - Surgery Supraventricular tachycardia - Sudden death Electrophysiology

\footnotetext{
Address reprint requests to: Macdonald Dick II MD, Division of Pediatric Cardiology, F1123 Box 0204, C. S. Mott Children's Hospital, University of Michigan Medical Center, 1500 East Medical Center Drive, Ann Arbor, MI 48109-0204, USA

Received July 18, 1988; revision received January 18, 1989; accepted January 20, 1989.
}

In 1930, Wolff, Parkinson, and White described 11 patients with palpitations and a short PR interval, wide QRS complex [QRS], and tachycardia on the electrocardiogram (WPW syndrome [WPW], preexcitation) [1]. Nine had the onset of symptoms during childhood or adolescence. The mechanisms proposed to explain the paroxysmal tachycardia and electrocardiographic findings included bundlebranch block and accelerated conduction through either the atrioventricular node or an accessory pathway [2]. The accessory atrioventricular connection, first proposed by Holzmann and Scherf [3], explained all the important features of the syndrome [4], including the atrioventricular reentrant tachycardia (ART), and was subsequently demonstrated [5] to be histologically similar to the earlier-described Kent bundle [6]. The symptoms of the WPW syndrome range from palpitations to syncope and, rarely, sudden death. Prophylaxis for the paroxsymal ART was initially directed toward pharmacologic alteration of conduction within either the atrioventricular node, the accessory connection, or both. However, division of the anomalous pathway can alleviate all symptoms of the syndrome. The surgical division of an accessory conduction pathway (Kent bundle) was first achieved in 1968 by Cobb and associates [7]. Since then, a number of reports have described the technique and results in adults [8-11]. However, only three other groups have reported surgical treatment of WPW in children [12-14]. This report examines the surgical management of WPW in children and young adults at our institution, outlines their clinical and electrophysiological characteristics and outcome, and discusses indications for surgery in this age group.

\section{Patients and methods}

\section{Patients}

During the past nine years, 24 children (age $\leq 18$ years) and 6 young adults (age 19-25 years) followed at our institution un- 
derwent surgical division of anomalous pathways (patients \#3 and $\# 4$ at a different institution). The clinical, electrocardiographic, electrophysiologic, and surgical data are outlined in Table 1 . There were 9 females and 19 males. Two of the patients had other cardiac abnormalities: one (patient \#13) had mild supravalvular aortic stenosis ( $25 \mathrm{mmHg}$ peak systolic gradient), and the other (patient \#2), tricuspid atresia, which was corrected (Fontan procedure) during the same operation [15].

\section{Clinical presentation}

Twenty-nine of the patients had the onset of palpitations associated with chest pain, faintness, and anxiety during childhood or adolescence as well as electrocardiographic changes consistent with preexcitation. One infant (\#1) presented in severe congestive heart failure [16]. Twenty-nine of the patients had multiple episodes of sustained symptomatic ART. The remaining patient (\#16) presented with a single episode of palpitations and a very rapid, wide QRS tachycardia on the electrocardiogram. Atrial fibrillation with anterograde conduction through the accessory connection was observed in the emergency room, followed by deterioration into ventricular fibrillation, requiring emergency defibrillation. Five additional patients had documented spontaneous atrial fibrillation; this rhythm deteriorated in three of these patients to documented ventricular fibrillation. Seven patients experienced syncope or presyncope.

\section{Drug therapy}

Twenty-three of the 30 patients with ART received empiric prophylactic drug therapy prior to referral to our institution. Seventeen $(57 \%)$ received a trial of digoxin $(10-15 \mathrm{mcg} / \mathrm{kg}$ daily), and $14(47 \%)$, a trial of quinidine (20-65 $\mathrm{mg} / \mathrm{kg}$ daily). Beta blockers (propranolol 2-4 $\mathrm{mg} / \mathrm{kg}$ daily; $12 / 30,40 \%$ ), verapamil ( $5-9 \mathrm{mg} / \mathrm{kg}$ daily; $8 / 30,27 \%)$, disopyramide $(2 \mathrm{mg} / \mathrm{kg}$ daily; $4 / 30,13 \%)$, and procainamide $(10-40 \mathrm{mg} / \mathrm{kg}$ daily; $2 / 20)$ were also tried. Nineteen $(63 \%)$ patients were treated with several different drug regimens, whereas four received only single drug therapy. Seven patients, all among the most recent 10 patients seen, elected surgical treatment.

\section{Electrophysiologic evaluation}

Preoperative electrophysiologic studies were performed in all 30 patients (patients \#16 and \#29 were studied at other institutions); all medications had been withdrawn at least 5 half-lives of the respective drug(s) before the study. Electrode catheters were placed in the coronary sinus (or through a patent foramen ovale into the left atrium), right atrium, and across the tricuspid valve (except patient \#2) for recording of intracardiac elcctrograms and delivery of programmed extrastimuli. The effective refractory period (ERP) of the accessory connection in the anterograde direction was determined by introducing an extrastimulus coupled to a constant drive cycle length (500 or 600 $\mathrm{ms}$ ) at progressively more premature intervals during diastole, until there was loss of preexcitation. Rapid atrial pacing was performed and/or atrial fibrillation was induced to determine the shortest RR interval (RR) with $1: 1$ conduction through the accessory connection to the ventricles. To locate the accessory connection within the atrioventricular ring, the earliest site of retrograde atrial activation recorded through bipolar pairs of electrodes (10 $\mathrm{mm}$ inter-electrode distance) during supraventricular tachycardia (SVT) was identified.

\section{Surgical management}

In the 28 patients operated on at our institution, the surgical approach consisted of either sternotomy (25 patients) or right thoracotomy ( 3 patients). Intraoperative electrophysiologic study using a hand-held electrode probe was performed to localize the accessory pathway. During atrial pacing at a rate that maximized preexcitation, the ventricular epicardium was mapped by comparing the measured local activation times near the atrioventricular groove. The area of earliest excitation on the ventricle corresponded to the ventricular insertion of the accessory pathway. The atrium was mapped in an analogous manner during ART (or ventricular pacing when ART was not sustained). Thus, the anomalous connection was localized to a specific site (approx. $5 \mathrm{~mm}$ ) along the atrioventricular ring.

Standard bicaval cardiopulmonary bypass with moderate systemic hypothermia and cold cardioplegic arrest was used. Right free wall and posterior septal pathways were approached from the right atrium, whereas the left free wall pathways were divided through a left atriotomy. The atrial endocardium was incised $2 \mathrm{~mm}$ above the atrioventricular valve annulus and continued $1-2 \mathrm{~cm}$ to either side of the accessory connection location. In the last 15 patients in this series, the dissection was extended to include the entire anatomic space containing the accessory connection. The plane between the atrioventricular groove fat pad and the ventricular myocardium was separated until the epicardial reflection was reached throughout the entire length of the dissection. In patients with a posterior septal accessory connection, the fat pad in the pyramidal space bounded by the right fibrous trigone anteriorly, the mitral and tricuspid annuli laterally, and the epicardial reflection posteriorly was completely dissected. Each dissection was designed to interrupt any accessory fibers spanning the atrioventricular junction within the area of dissection.

After cardiopulmonary bypass was discontinued and sinus rhythm restored, atrial burst pacing was performed to assess both normal and persistently anomalous (if present) anterograde conduction. If preexcitation persisted, ventricular epicardial mapping was repeated to identify additional or incompletely divided accessory connections. If present (and after localization), division of the additional pathway(s) was performed. Anomalous ventriculo-atrial (retrograde) conduction was also examined by ventricular pacing and atrial mapping.

\section{Postoperative studies and follow-up}

All the patients had exteriorized atrial and ventricular electrode wires placed at the end of surgery; electrophysiologic studies using the same protocol employed preoperatively were performed through these wire electrodes. Four of the patients received postoperative electrophysiologic study 6-24 months after surgery. Information regarding follow-up, including electrocardiograms, was available from all 30 patients.

\section{Statistical analysis}

All electrophysiologic data are presented as the mean and one standard deviation. For purposes of analysis the patients were assigned to two groups: those with syncope and those without. Differences in the mean between groups were assessed using analysis of variance as well as the Kruskal-Wallis test for continuous variables and the Fisher exact test for categorical variables. Differences were considered significant if the $P$ value was equal to or less than 0.05 . 
Table 1. Data on patients who underwent surgical division of anomalous pathways

\begin{tabular}{|c|c|c|c|c|c|c|c|c|c|}
\hline Patient & Sex & Arrhythmias & $\begin{array}{l}\text { Life- } \\
\text { threatening } \\
\text { tachycardia }\end{array}$ & Drug therapy & $\begin{array}{l}\text { Age at } \\
\text { surgery } \\
\text { (years) }\end{array}$ & $\begin{array}{l}\text { Accessory } \\
\text { connection }\end{array}$ & $\begin{array}{l}\text { ERP } \\
\text { (ms) }\end{array}$ & $\begin{array}{l}\text { RR interval } \\
\text { (AF/pace) } \\
\text { (ms) }\end{array}$ & $\begin{array}{l}\text { Postoperative } \\
\text { status }\end{array}$ \\
\hline$\# 1$ & $\mathbf{M}$. & $\begin{array}{c}\text { AF, VF, } \\
\text { CHF }\end{array}$ & Yes & $\begin{array}{l}\text { DIG, Q, V, P, } \\
\text { DISO }\end{array}$ & 3 (month) & $\begin{array}{c}\text { Multiple, left } \\
\text { Free wall }\end{array}$ & NA & $240 / \mathrm{NA}$ & $\begin{array}{l}\text { WPW. SVT } \\
\text { Sick sinus }\end{array}$ \\
\hline$\not 2$ & $\mathbf{F}$ & $\begin{array}{l}\text { Palpitations, } \\
\text { faintness }\end{array}$ & No & DIG, Q, P & 18 & $\begin{array}{l}\text { Right free } \\
\text { wall }\end{array}$ & 450 & $\mathrm{NA} / 500$ & $\begin{array}{l}\text { No WPW } \\
\text { No SVT, } \\
\text { AF }\end{array}$ \\
\hline$\# 3$ & $\mathbf{M}$ & $\begin{array}{l}\text { Palpitations, } \\
\text { chest pain }\end{array}$ & No & DIG, Q, P & 17 & $\begin{array}{l}\text { Right anterior } \\
\text { septal }\end{array}$ & 300 & $500 / \mathrm{NA}$ & $\begin{array}{c}\text { No WPW } \\
\text { No SVT }\end{array}$ \\
\hline$\# 4$ & $F$ & $\begin{array}{l}\text { Palpitations, } \\
\text { syncope, } \mathrm{AF}\end{array}$ & Yes & DIG, Q, DISO & 16 & Left free wall & 260 & $180 / 250$ & $\begin{array}{c}\text { No WPW } \\
\text { No SVT }\end{array}$ \\
\hline$\# 5$ & $\mathbf{F}$ & $\begin{array}{l}\text { Palpitations, } \\
\text { chest pain }\end{array}$ & No & DIG, Q, DISO & 25 & $\begin{array}{c}\text { Posterior } \\
\text { septal }\end{array}$ & 322 & NA/355 & $\begin{array}{c}\text { No WPW } \\
\text { No SVT }\end{array}$ \\
\hline$\# 6$ & M & $\begin{array}{l}\text { Palpitations, } \\
\text { syncope, AF }\end{array}$ & Yes & DIG, P, DISO & 24 & $\begin{array}{l}\text { Left free wall, } \\
\text { multiple }\end{array}$ & 270 & $180 / 180$ & WPW SVT \\
\hline$\# 7$ & $\mathbf{M}$ & Palpitations, & No & DIG, Q & 17 & Left free wall & 240 & $370 / 400$ & $\begin{array}{c}\text { No WPW } \\
\text { No SVT }\end{array}$ \\
\hline$\# 8$ & M & $\begin{array}{l}\text { Palpitations, } \\
\text { syncope, VF }\end{array}$ & Yes & DIG, P. PR, V & 15 & $\begin{array}{l}\text { Right and left } \\
\text { free wall }\end{array}$ & $\begin{array}{r}\text { Right } 295 \\
\text { Left } 295\end{array}$ & $240 / 245$ & $\begin{array}{c}\text { No WPW } \\
\text { No SVT }\end{array}$ \\
\hline$\# 9$ & $\mathbf{M}$ & $\begin{array}{l}\text { Palpitations, } \\
\text { faintness }\end{array}$ & No & $\mathrm{Q}, \mathrm{P}$ & 16 & Left free wall & 375 & $300 / 240$ & $\begin{array}{c}\text { No WPW } \\
\text { No SVT }\end{array}$ \\
\hline$\# 10$ & M & $\begin{array}{l}\text { Palpitations, } \\
\text { chest pain, } \\
\text { syncope }\end{array}$ & Yes & DIG & 16 & $\begin{array}{l}\text { Posterior } \\
\text { septal }\end{array}$ & 255 & $300 / 290$ & $\begin{array}{l}\text { No WPW } \\
\text { SVT }\end{array}$ \\
\hline$\# 11$ & $F$ & Palpitations & No & DIG & 15 & Left free wall & 290 & $350 / 280$ & $\begin{array}{l}\text { No WPW } \\
\text { No SVT }\end{array}$ \\
\hline$\# 12$ & $\mathrm{~F}$ & Palpitations & No & DIG, P & 15 & Left free wall & 210 & $210 / 230$ & $\begin{array}{l}\text { No WPW } \\
\text { No SVT }\end{array}$ \\
\hline$\# 13$ & $\mathrm{~F}$ & Palpitations & No & DIG, V & 17 & Left free wall & 220 & $\mathrm{NA} / 280$ & $\begin{array}{c}\text { No WPW } \\
\text { No SVT }\end{array}$ \\
\hline$\# 14$ & $\mathrm{~F}$ & Palpitations & No & $\mathrm{DIG}, \mathrm{Q}, \mathrm{P}, \mathrm{V}$ & 10 & $\begin{array}{l}\text { Right and left } \\
\text { free wall }\end{array}$ & $\begin{array}{r}\text { Right } 330, \\
\text { Left } 280\end{array}$ & NA/310 & $\begin{array}{c}\text { No WPW } \\
\text { No SVT }\end{array}$ \\
\hline$\# 15$ & $\mathbf{M}$ & Palpitations & No & $\mathrm{Q}, \mathbf{P}$ & 4 & $\begin{array}{l}\text { Right free } \\
\text { wall }\end{array}$ & 320 & NA/ 600 & $\begin{array}{c}\text { No WPW } \\
\text { No SVT }\end{array}$ \\
\hline$\# 16$ & $\mathbf{M}$ & $\begin{array}{l}\text { Syncope, AF, } \\
\text { VF }\end{array}$ & Yes & $\mathbf{Q}, \mathbf{P}$ & 14 & Left free wall & 220 & $170 / \mathrm{NA}$ & $\begin{array}{l}\text { No WPW } \\
\text { No SVT }\end{array}$ \\
\hline$\# 17$ & $\mathbf{F}$ & Palpitations & No & $\mathrm{DIG}, \mathrm{Q}, \mathrm{P}, \mathrm{V}$ & 18 & Left free wall & 460 & $350 / 310$ & $\begin{array}{l}\text { No WPW } \\
\text { No SVT }\end{array}$ \\
\hline$\# 18$ & $\mathbf{M}$ & $\begin{array}{l}\text { Palpitations, } \\
\text { faintness }\end{array}$ & No & DIG, P, Q, V & 7 & $\begin{array}{l}\text { Left free wall, } \\
\text { multiple }\end{array}$ & 200 & $300 / 240$ & $\begin{array}{l}\text { No WPW } \\
\text { No SVT }\end{array}$ \\
\hline$\# 19$ & $\mathbf{F}$ & $\begin{array}{l}\text { Palpitations, } \\
\text { faintness }\end{array}$ & No & None & 17 & Left free wall & 210 & $280 / \mathrm{NA}$ & $\begin{array}{l}\text { No WPW } \\
\text { No SVT }\end{array}$ \\
\hline$\# 20$ & $\mathbf{F}$ & $\begin{array}{l}\text { Palpitations, } \\
\text { faintness }\end{array}$ & No & None & 11 & $\begin{array}{l}\text { Right free } \\
\text { wall }\end{array}$ & 240 & $240 / 240$ & $\begin{array}{l}\text { No WPW } \\
\text { No SVT }\end{array}$ \\
\hline$\# 21$ & $\mathbf{M}$ & $\begin{array}{l}\text { Palpitations } \\
\text { associated } \\
\text { with exercise }\end{array}$ & No & None & 15 & $\begin{array}{l}\text { Right free } \\
\text { wall }\end{array}$ & 600 & $\begin{array}{l}\text { No preexcita- } \\
\text { tion with AF } \\
\text { or pace }\end{array}$ & $\begin{array}{l}\text { No WPW } \\
\text { No SVT }\end{array}$ \\
\hline$\# 22$ & $\mathbf{F}$ & Palpitations & No & DIG, P & 11 & $\begin{array}{l}\text { Right free } \\
\text { wall, Post } \\
\text { septal }\end{array}$ & $\begin{array}{r}\text { Right } 370, \\
\text { Left } 600\end{array}$ & $\begin{array}{l}\text { No preexcita- } \\
\text { tion }\end{array}$ & $\begin{array}{l}\text { No WPW } \\
\text { No SVT }\end{array}$ \\
\hline$\# 23$ & $\mathbf{M}$ & $\begin{array}{c}\text { Palpitations, } \\
\text { AF, VF }\end{array}$ & No & $P, V, P R$ & 20 & $\begin{array}{l}\text { Post septal } \\
\text { left }\end{array}$ & $<220$ & $160 / 250$ & WPW SVT \\
\hline$\# 24$ & $\mathbf{M}$ & Palpitations & No & None & 19 & Post septal & 290 & $230 / 290$ & $\begin{array}{c}\text { No WPW } \\
\text { No SVT }\end{array}$ \\
\hline$\# 25$ & $\mathbf{M}$ & Palpitations & No & $\mathrm{Q}, \mathrm{V}$ & 21 & $\begin{array}{l}\text { Post septal } \\
\text { left }\end{array}$ & 190 & $230 / 400$ & $\begin{array}{l}\text { No WPW } \\
\text { No SVT }\end{array}$ \\
\hline$\# 26$ & M & Palpitations & No & $Q$ & 17 & Left free wall & 290 & NA/400 & $\begin{array}{l}\text { No WPW } \\
\text { No SVT }\end{array}$ \\
\hline$\# 27$ & $\mathbf{M}$ & Palpitations & No & None & 18 & $\begin{array}{l}\text { Post septal } \\
\text { left }\end{array}$ & $<260$ & $380 / 280$ & $\begin{array}{c}\text { No WPW } \\
\text { No SVT }\end{array}$ \\
\hline$\# 28$ & $\mathbf{M}$ & Palpitations & No & None & 21 & Left free wall & 250 & $280 / 300$ & $\begin{array}{l}\text { No WPW } \\
\text { SVT }\end{array}$ \\
\hline$\# 29$ & $\mathbf{M}$ & Palpitations & No & DIG & 17 & $\begin{array}{l}\text { Right free } \\
\text { wall }\end{array}$ & NA & NA/NA & $\begin{array}{c}\text { No WPW } \\
\text { No SVT }\end{array}$ \\
\hline$\# 30$ & M & $\begin{array}{l}\text { Palpitations, } \\
\text { hypotension, } \\
\text { dizzness, } \\
\text { counter- } \\
\text { shock }\end{array}$ & No & None & 18 & $\begin{array}{l}\text { Right free } \\
\text { wall }\end{array}$ & $\begin{array}{r}\text { Right } 250, \\
\text { Left } 600\end{array}$ & $190 / 300$ & $\begin{array}{l}\text { No WPW } \\
\text { No SVT }\end{array}$ \\
\hline
\end{tabular}




\section{Results}

Although trends were noted suggesting differences in the electrophysiologic properties of the accessory connection between the patients whose symptoms included syncope and those whose symptoms did not, most of these differences did not reach significance; this was, in part, due to the small number of patients along with the wider range of values in the non-syncopal group. The preoperative electrophysiologic studies demonstrated a mean antegrade ERP in the accessory connection of $251 \pm 27 \mathrm{~ms}$ (range, 220-295 ms) in those patients with syncope compared to $300 \pm 100 \mathrm{~ms}$ (range, $190-600 \mathrm{~ms}$ ) among those without syncope $(P=$ ns). Likewise, the mean $\mathrm{RR}$ interval with preexcitation during rapid atrial pacing ipsilateral to the accessory connection $(243 \pm 40 \mathrm{~ms}$ [range, $180-290 \mathrm{~ms}$ ] versus $327 \pm 99 \mathrm{~ms}$ [range, $230-600 \mathrm{~ms}$; $P=0.08, n=22$ ) tended to be shorter in those patients with syncope compared to those without syncope, but not to a significant degree. In contrast, the shortest RR interval obtained during induced or spontaneous atrial fibrillation (205 $\pm 54 \mathrm{~ms}$ [range, $160-300 \mathrm{~ms}$ ] versus $300 \pm 84 \mathrm{~ms}$ [range, $190-500 \mathrm{~ms}$ ]; $P=.02$, $n=20$ ) was significantly shorter in those patients with syncope compared to those without. A similar trend that did not reach significance was found in these values between patients with either single or multiple accessory connections.

The transcatheter and intraoperative mapping procedures located 36 accessory pathways in the 30 patients. A single left-sided free wall pathway occurred in $11(37 \%)$ of the patients. An isolated right free wall pathway was found in 6 patients. Two patients had both a right and left free wall pathway; six had pathways located in the posterior septum, and in one the pathway was found in the anterior septum. Six patients had more than one pathwaythe two mentioned above, three with multiple leftsided tracts, and one with a tract in both the right free wall and the posterior septum. The anatomic distribution of the anomalous pathways in this group of children was similar to that found in other series $[12,17]$. Four of the six patients with multiple pathways experienced either syncope or spontaneous atrial fibrillation/ventricular fibrillation; these associations did reach significance $(P=0.02$ and $P=$ 0.01 , respectively) by the Fisher exact test.

Twenty-seven of the 30 patients $(90 \%)$ have had no further symptoms of WPW syndrome following surgery; all 30 have intact atrioventricular conduction, postoperatively. To avoid the more visible scar of a median sternotomy, three adolescent girls with left lateral pathways elected a right thoracotomy; their early postoperative course was not different in duration or outcome from those patients ap- proached through a median sternotomy. However, one girl has had persistent pain along the incision line, compatible with a surgically induced peripheral neutopathy. Two other patients have experienced surgical complications, for a total of three $(10 \%)$. One patient developed the post-pericardiotomy syndrome which responded to anti-inflammatory therapy without residua. Another patient experienced postoperative hemorrhage into the right pleural cavity, resulting in cardiac arrest, followed by successful resuscitation.

Three patients represent a failure of the technique. Our first patient, an infant, experienced recurrent ART three days after surgery, and at 22 months of age he developed sick sinus syndrome requiring a pacemaker. Two other patients developed recurrent preexcitation and ART 4-12 weeks after surgery. In one, mitral regurgitation and a left posterior-lateral wall motion abnormality were noted at postoperative catheterization, suggesting an intraoperative injury to that segment of the left ventricular wall; he has no symptoms related to this finding. Patient \#1 had one-to-one atrioventricular conduction blocks at atrial rates above $200 \mathrm{bpm}$. In patient \#6, the shortest preexcited RR interval during atrial fibrillation was $210 \mathrm{~ms}$ before the operation and $310 \mathrm{~ms}$ after the operation (both after procainamide infusion). The third patient has refused further evaluation. All three have been clinically free of rapid anterograde conduction across the atrioventricular junction 1-9 years following surgery.

Three patients have developed a later, different form of supraventricular tachycardia. Patient \#2 developed atrial fibrillation related to her congenital heart disease; postoperative electrophysiologic study excluded persistence of an accessory pathway. Patients \#10 and \#28 developed a slower, nonsustained, narrow QRS SVT 3 years and 6 months later, respectively. Electrophysiologic study demonstrated atriventricular nodal tachycardia and no evidence of an accessory pathway in patient \#28. Patient \#10 has declined further study. All three patients have no preexcitation on the electrocardiogram.

\section{Discussion}

Although the reported incidence of SVT in children is reported to be low $(1 / 25,000)$, more recent experience suggests a higher frequency [18]. At our institution, $3.5 \%$ of patients referred for cardiac evaluation (10,500 patients) have SVT. Approximately $50 \%$ of these patients have either manifest (i.e., WPW syndrome) or concealed accessory pathways supporting the tachycardia (ART) [19]. Although ART and WPW are both well known in infants 
[20-25] and are usually, but not always [16], benign, especially in the absence of structural heart disease, the tachycardia may either first occur or even reappear in the older child and adolescent. Thus WPW, as first described by Wolff, Parkinson, and White, is often a problem of the young. Possible factors which may have militated against definitive surgical treatment in this age group in the past are the favorable natural history of this disorder, particularly in the infant, the paroxysmal character of the disorder making the definitive diagnosis elusive, an incomplete understanding of the tachycardia, infrequency of atrial fibrillation in the young, the absence of associated heart disease in the young, empiric drug therapy, the invasive as well as the time-, labor-, and technology-intensive character of the arrhythmia analysis, both in the laboratory and the operating room, and the attendant surgical morbidity and potential mortality. The experience of $90 \%$ freedom from SVT and preexcitation among our patients receiving operations, along with both the similar surgical $(86 \%-98 \%)$ experience of others [8-14] and the recognized problems of side-effects and compliance in the use of anti-arrhythmic medications [17, 26-28], in large part, overcomes these reservations and argues strongly for surgical treatment of this disorder in the young.

Surgery was unsuccessful in 3 patients. Left-sided pathways were identified at two sites along the left atrioventricular groove in 2 patients; even after extensive dissection through the left atrium, preexcitation and ART returned. The third patient had a pathway located deep(leftward) in the posterior septum. We have extended the surgical approach to this accessory connection location to include a right atrial approach to the posterior left aspect of the pyramidal space. Postoperatively, patients \#1 and \# 5 have undergone electrophysiologic study. Both had much slower anterograde conduction across the accessory connection, and neither has had a recurrence of ventricular fibrillation. Therefore, of the seven patients with syncope and potentially fatal arrhythmias, 6 of the 7 are known to be free of their life-threatening arrhythmias.

The appearance of late arrhythmias in 3 patients which were not directly related to the WPW syndrome is unexpected, especially in the two patients without associated structural heart disease. Although neither patient had evidence of another form of tachycardia at electrophysiologic study, it is well known that more than one form of SVT can occur in a single patient with WPW [29]. Whether the appearance of these late arrhythmias is related to potential surgical alteration in the electrophysiologic properties of the atrioventricular conduction system, or to the aforementioned association of several forms of tachycardia, is unknown.
The comparison of the electrophysiologic data between the children with syncope and those without was similar to those reported in older patients by Klein [30] and relates to the important question of risk for sudden death. Although the mean anterograde effective refractory period of the accessory pathway of our patients with syncope tended to be shorter than that in patients without syncope, 9 of the 23 patients without syncope exhibited short ( $\leq 250 \mathrm{~ms}$ ) anterograde effective refractory periods. Further, and more importantly, 5 non-syncopal patients exhibited a consecutive preexcited RR interval $\leq 250 \mathrm{~ms}$ during induced atrial fibrillation, clearly identifying a group of young patients at theoretical risk for sudden death if clinical atrial fibrillation should appear. Several investigators have noted increased atrial vulnerability or susceptibility to atrial fibrillation in older patients with frequent episodes of ART [31, 32]. On the other hand, in part because of the smaller atria, atrial fibrillation occurs infrequently in infants with WPW $[16,33]$. Our 7 patients with syncope represent those individuals at greatest risk for sudden death. Four of our five patients with syncope and spontaneous atrial fibrillation had fast anterograde conduction across the accessory connection; the patients with only induced, but not spontaneous, atrial fibrillation and fast conduction are presumably at risk if spontaneous atrial fibrillation occurs. Importantly, as illustrated by patient \#16 as well as by patients reported elsewhere [34, 35], the initial presentation of young people with the WPW syndrome can be a catastrophic event, enhanced, perhaps, by an exercise-related catecholamine surge. Rinne and associates [36] have reported that up to $50 \%$ of patients with unproven symptoms (undocumented palpitations) may have fast anterograde conduction properties ( $R R$ interval during atrial fibrillation $\leq 250 \mathrm{~ms}$ ) in the accessory connection, whereas Milstein et al. [37] have noted that up to $17 \%$ of asymptomatic patients with WPW may exhibit fast anterograde conduction across the accessory connection.

\section{Implications}

Prospective management of patients with WPW syndrome would be improved by the definition of risk; Klein et al. [30, 38], Wellens et al. [39, 40], Rinne et al. [36], and Sharma et al. [41] have examined a number of factors that impact patient risk. The occurrence of a short anterograde effective refractory period in the accessory connection, frequent fast ART, the shortest consecutive preexcited RR interval during spontaneous atrial fibrillation, the individual autonomic state, and enhanced atrial vulnerability may contribute to risk in the individual 
patient. However, the sensitivity of the shortest consecutive preexcited RR interval during spontaneous atrial fibrillation is only moderate $(78 \%)$, whereas the correlation between the shortest preexcited RR interval during atrial fibrillation and the anterograde effective refractory period of the accessory connection is variable $(r=.39-.7)[39,41]$. Furthermore, the specificity and accuracy of the shortest consecutive preexcited RR interval to predict who is at risk for sudden death is reported to be low ( $49 \%$ and $19 \%$, respectively). An improved sensitivity $(91 \%)$ is achieved by examining the response of preexcitation to both an exercise test and a type I anti-arrhythmic medication infusion; however, this combination does not improve specificity [41]. On the other hand, because slow conduction across the accessory pathway will prevent a rapid ventricular response to atrial fibrillation, should it develop, these variables do identify patients who are not at risk for sudden death.

Recognizing the incompleteness of information regarding the natural history of WPW as well as the infrequency of spontaneous atrial fibrillation in the young, we have developed an algorithm (Fig. 1) to assist in the management of WPW in our young population. If preexcitation is intermittent on the ECG or disappears with exercise or with pro- cainamide or disopyramide infusion $[26,36,41]$, one may conclude that the accessory connection is not a fast conductor. Further, if the patient's episodes of ART are brief $(\leq 5-10 \mathrm{~min}$ ), occur infrequently ( $\leq 3-4$ times a year) and are self-limiting (terminated by a vagal maneuver) so as to be minimally symptomatic, the patient and family may choose to do nothing (Fig. 1A). If preexcitation is not intermittent and persists through exercise and high heart rates ( $\geq 180 \mathrm{bpm}$ ), rapid atrial pacing and/or induction of atrial fibrillation through either the esophageal or intra-cardiac route should be considered to examine the conduction properties of the accessory connection. If rapid conduction is present during pacing or atrial fibrillation, treatment is then similar to that of more symptomatic patients (Fig. 1B). If conduction is slow during atrial fibrillation, either no treatment or empiric treatment with type I or type II anti-arrhythmic medications may be tried (digoxin should be used only after electrophysiologic study of its effect in this older group). If significant symptoms are present with or without persistence of preexcitation with exercise (Fig. 1B), the electrophysiologic characteristics of the accessory pathway should be determined and appropriate pharmacological or surgical therapy directed toward prophylaxis of both the ART and rapid

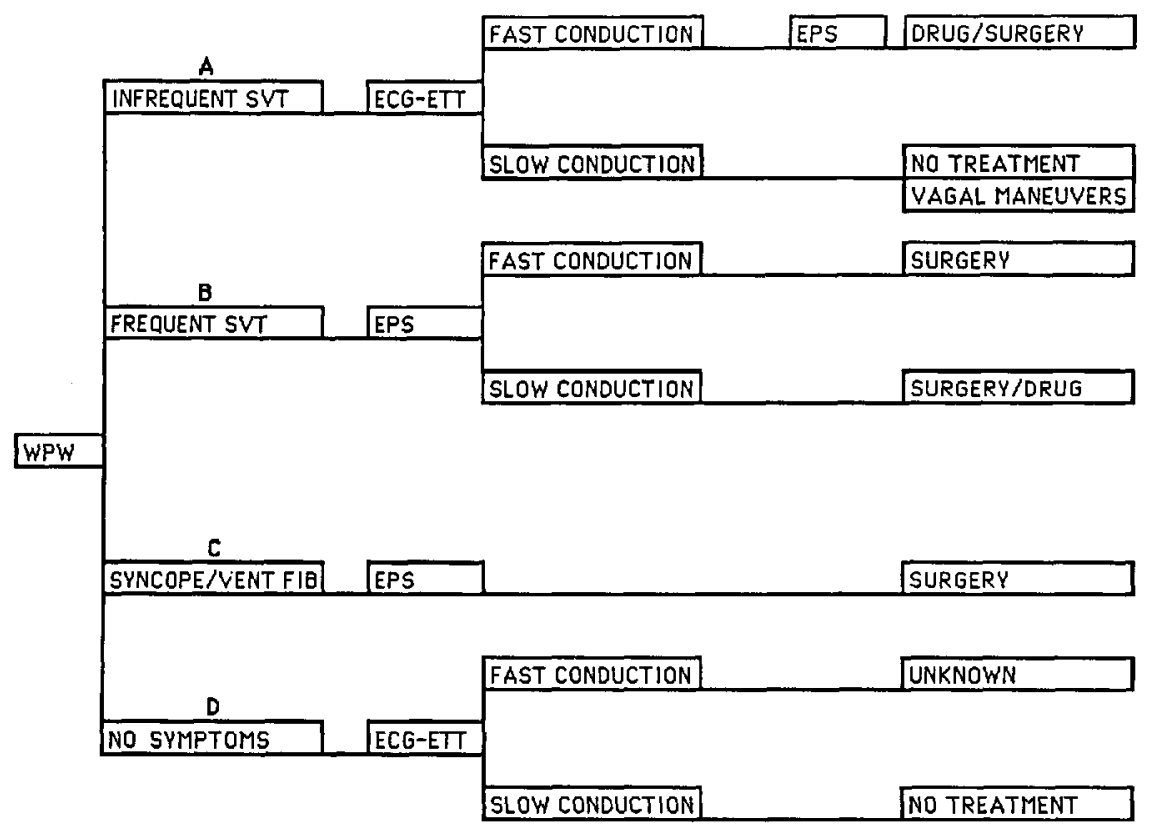

Fig. 1. This algorithm outlines a proposed course of action in children noted to exhibit preexcitation on the electrocardiogram. The initial branches of the decision tree are dependent upon symptoms and mode of presentation. As symptoms change or appear, patients may move from limb to limb until definitive treatment is determined and achieved. ECG, electrocardiogram; EPS, electrophysiologic study; ETT, exercise treadmill testing; $S V T$, supraventricular tachycardia; VENT FIB, ventricular fibrillation; $W P W$, Wolff-Parkinson-White 
conduction across the accessory connection when present. If the patient has experienced documented atrial fibrillation with a rapid ventricular response across the accessory connection, ventricular fibrillation, or unexplained syncope (Figure 1C), surgery, preceded by electrophysiologic study, is indicated. It is important to note that these recommendations do not address the patient with fast conductiondetermined by the measures outlined - but with no symptoms (Figure 1D). Owing to the rarity of sudden deaths $(0 \%-4 \%)$ [35] in older individuals with WPW, the even lower probable risk below the teenage years in the absence of heart disease [20-24], and the lack of specificity in identifying patients at risk, decisions regarding evaluation and treatment in these unusual patients must at present be individualized and perhaps considered investigational [42]. Although asymptomatic (i.e., no tachycardia) patients with both the WPW syndrome and fast conducting accessory pathways appear to be at risk for sudden death, and thus would possibly benefit from surgery in a manner similar to patients with an atrial septal defect or aortic stenosis who undergo surgery for the prevention of pulmonary vascular obstructive disease or sudden death, respectively, the natural history of this subset of WPW patients is not sufficiently characterized to justify a recommendation of surgery at this time.

In conclusion, this experience along with that of others is sufficiently comprehensive to advise surgical treatment for all patients with WPW syndrome and unexplained syncope, atrial fibrillation with fast anterograde conduction across the accessory connection, and/or documented ventricular frbrillation, regardless of age. In addition, the frequency of SVT in the young, the low, unquantified but real risk of sudden death, and the proven effectiveness and safety of definitive treatment grounded in electrophysiologic principles argues persuasively that surgical division of the accessory connection is an acceptable, and perhaps the preferred, treatment for selected young patients with WPW and ART.

\section{References}

1. Wolff L, Parkinson J, White PD (1930) Bundle branch block with short $\mathrm{P}-\mathrm{R}$ interval in healthy young people prone to paroxysmal tachycardia. Am Heart J 5: 685-704

2. Zipes DP, Rothbaum DA, DeJoseph RL (1974) Pre-excitation syndrome. Cardiovasc Clin 6 (Suppl I): T-209-243

3. Holzmann M, Scherf D (1932) Uber Elektrokardiogramme mit verkurzter Vorhof-Kammer-Distanz und positiven PZacken. Ztschr Klin Med 121: 404-423

4. Wolferth CC, Wood FC (1933) The mechanism of production of short P-R intervals and prolonged QRS complexes in patients with presumably undamaged hearts: Hypothesis of an accessory pathway of auriculoventricular conduction (bundle of Kent). Am Heart J 8: 297-311

5. Wood FC, Wolferth CC, Geckeler GD (1943) Histologic demonstration of accessory muscular connections between auricle and ventricle in a case of short P-R interval and prolonged QRS complex. Am Heart J 25:454-462

6. Kent AFS (1893) Researches on the structure and function of the mammalian heart. J Physiology 14:233-254

7. Cobb FR, Blumenschein SD, Sealy WC, Boineau JP, Wagner GS, Wallace AG (1968) Successful surgical interruption of the bundle of Kent in a patient with WolffParkinson-White syndrome. Circulation 38: 1018-1029

8. Sealy WC, Gallagher JJ, Wallace AG (1976) The surgical treatment of Wolff-Parkinson-White syndrome: Evolution of improved methods for identification of interruption of the Kent bundle. Ann Thorac Surg 22 (Suppl V): V-443456

9. Holmes DR, Osborn MJ, Gersh B, Maloney JD, Danielson GK (1982) The Wolff-Parkinson-White syndrome; A surgical approach. Mayo Clin Proc 57:345-350

10. Cox JL (1983) Surgery for cardiac arrhythmias. Curr Prob Cardiol 8 (Suppl IV): IV-1-60

11. Lawric GM, Lin HT, Wyndham CRC, DeBakey ME (1987) Surgical treatment of supraventricular arrhythmias. Ann Surg 205 (Suppl VI): VI-700-711

12. Ott DA, Garson A, Cooley DA, McNamara DG (1985) Definitive operation for refractory cardiac tachyarrhythmias in children. J Thorac Cardiovasc Surg 90: 681689

13. Erickson CC, Kugler JD, Cheatham JP, Latson LA, Gumbiner CH, Hofschire PJ, Fleming WH (1986) Surgical treatment of children and adolescents with Wolff-ParkinsonWhite syndrome. Nebr Med J 71: 350-356

14. Holmes DR Jr, Danielson GK, Gersh BJ, Osborn, MJ, Wood DL, McLaran C, Sugrue DD, Porter CJ, Hammill SC (1985) Surgical treatment of accessory atrioventricular pathways and symptomatic tachycardia in children and young adults. Am J Cardiol 55: 1509-1512

15. Dick M, Behrendt DM, Byrum CJ, Sealy WC, Stern AM, Hees P, Rosenthal A (1981) Tricuspid atresia and the WolffParkinson-White syndrome: Evaluation methodology and successful surgical treatment of the combined disorders. Am Heart J 101 (Suppl IV): IV-496-500

16. Byrum CJ, Wahl RA, Behrendt DM, (1982) Ventricular fibrillation associated with use of digitalis in a newborn infant with Wolff-Parkinson-White syndrome. J Pediatr 101 (Suppl III): III-400-403

17. Gallagher JJ, Selle JG, Svenson RH, (1988) Surgical treatment of arrhythmias. Am J Cardiol 61: A27-A44

18. Garson A, Gillette PC, McNamara DG (1981) Supraventricular tachycardia in children: Clinical features, response to treatment, and long-term follow-up in 217 patients. J Pediatr 98 (Suppl VI): VI-875-872

19. Campbell RM, Dick M, Rosenthal A (1984) Cardiac arrhythmias in children. Annu Rev Med 35: 397--410

20. Giardina ACV, Ehlers KH, Engle MA (1972) WolffParkinson-White syndrome in infants and children. $\mathrm{Br}$ Heart J 34: 839-846

21. Wolff GS, Han J, Curran J (1978) Wolff-Parkinson-White syndrome in the Neonate. Am J Cardiol 41:559-563

22. Manatakas ME, McCue CM, Miller WW (1978) Natural History of Wolff-Parkinson-White syndrome discovered in infancy. Am J Cardiol 41: 1097-1103

23. Lundberg A (1982) Paroxysmal atrial tachycardia in infancy: Long-term follow-up study of 49 subjects. Pediatrics 70 (Suppl IV): IV-638-642

24. Deal BJ, Keane JF, Gillette PC, Garson A (1985) WolffParkinson-White syndrome and supraventricular tachycardia during infancy: Management and follow-up. J Am Coll Cardiol 5 (Suppl I): I-130-135 
25. Dick M, Campbell RM (1984) Advances in the management of cardiac arrhythmias in children. Pediatr Clin North Am 31 (Suppl VI): VI-1175-1195

26. Klein GJ, Sharma AD, Yee R (1988) An approach to therapy for paroxysmal supraventricular tachycardia. Am J Cardiol 61: A77-A82

27. Campbell RM, Hammon JW, Echt DS, Graham TP (1987) Surgical treatment of pediatric cardiac arrhythmia. J Pediatr 110 (Suppl IV): IV-501-508

28. Castellanos A, Myerburg RJ (1987) Changing perspectives in the preexcitation syndromes. (editorial) $\mathrm{N}$ Engl J Med 317: 109-111

29. Princhette ELC, Prystowsky EN, Benditt DG, Gallagher JJ (1980) "Dual Atrioventricular Nodal Pathways" in Patients with Wolff-Parkinson-White Syndrome. Br Heart J 43; $7-13$

30. Klein GJ, Bashore TM, Sellers TD, Pritchett ELC, Smith WM, Gallagher JJ (1979) Ventricular fibrillation in the Wolff-Parkinson-White syndrome. N Engl J Med 301 (Suppl XX): XX-1080-1085

31. Sung RJ, Castellanos A, Mallon SM, Bloom MG, Gelband H. Myerburg RJ (1977) Mechanisms of spontaneous alternation between reciprocating tachycardia and atrial futterfibrillation in the Wolff-Parkinson-White syndrome. Circulation 56 (Suppl III): III-409-416

32. Waspe LE, Brodman R, Kim SG, Fisher JD (1986) Susceptibility to atrial fibrillation and ventricular tachyarrhythmia in the Wolff-Parkinson-White syndrome: Role of the accessory pathway. Am Heart J 112 (SuppI VI): VI-1141-1152

33. Gillette PL, Garson A, Kugler JD (1979) Wolff-ParkinsonWhite syndrome in children: Electrophysiologic and pharmacologic characteristics. Circulation 60: 1487-1495

34. Cosio FG, Benson DW, Anderson RW, Hession WT,
Pritzker MR, Kriett JM, Benditt DG (1982) Onset of atrial fibrillation during antidromic tachycardia: Association with sudden cardiac arrest and ventricular fibrillation in a patient with Wolff-Parkinson-White syndrome. Am J Cardiol 50:353-359

35. Wiedermann CJ, Becker AE, Hopferwieser T, Muhlberger $V$, Knapp $E$ (1987) Sudden death in a young competitive athlete with Wolff-Parkinson-White syndrome. Heart $\mathrm{J} 8$ : $651-655$

36. Rinne C, Klein GJ, Sharma AD, Yee R, Milstein S. Rattes MF (1987) Relation between clinical presentation and induced arrhythmias in the Wolff-Parkinson-White syndrome. Am J Cardiol 60: 576-579

37. Milstein S, Sharma AD, Klein GJ (1986) Electrophysiologic profile of asymptomatic Wolff-Parkinson-White pattern. Am J Cardiol 57: 1097-1100

38. Klein GJ, Gulamhusein SS (1983) Intermittent preexcitation in the Wolff-Parkinson-White syndrome. Am J Cardiol 52: 292-296

39. Wellens HJ, Durrer D (1974) Wolf-Parkinson-White syndrome and atrial fibrillation. Am J Cardiol 34:777-782

40. Wellens HJ (1983) Wolff-Parkinson-White syndrome, Part I, Diagnosis, arrhythmias, and identification of the high risk patient. Mod Concepts Cardiovasc Dis 52 (Supples XI, XII): $53-59$

41. Sharma AD, Yee R, Guiraudon G, Klein GJ (1987) Sensitivity and specificity of invasive and noninvasive testing for risk of sudden death in Wolff-Parkinson-White syndrome. J Am Coll Cardiol 10 (SuppI II): II-373-381

42. Prystowsky EN (1988) Indications for intracardiac electrophysiologic studies in patients with supraventricular tachycardia. Circulation 75 (Suppl III): III-119-122 